\title{
Investigating the Effect of Various Nanomaterials on the Wettability of Sandstone Reservoir
}

\author{
El-Abbas Moustafa1, Ahmed Noah², Karam Beshay', Lamees Sultan², \\ Mina Essam², Omar Nouh² \\ ${ }^{1}$ Egyptian Petroleum Research Institute (EPRI), Cairo, Egypt \\ ${ }^{2}$ Petroleum and Energy Engineering Department, Faculty of Science and Engineering, The American University, \\ Cairo, Egypt \\ Email: moustafa abs@hotmail.com, karam.beshay@aucegypt.edu, alaanooh@hotmail.com
}

Received 14 April 2015; accepted 1 August 2015; published 4 August 2015

Copyright (c) 2015 by authors and Scientific Research Publishing Inc.

This work is licensed under the Creative Commons Attribution International License (CC BY). http://creativecommons.org/licenses/by/4.0/

(c) (i) Open Access

\section{Abstract}

Wettability is the ability of a fluid to stick to a solid surface in the presence of other immiscible fluids. Wettability alteration is crucial as it affects the amount of oil recovered from a given reservoir. The majority of enhanced oil recovery mechanisms purposefully alter the wettability of the reservoir rock from oil-wet to water-wet; to increase the amount of oil recovered from it. This study investigates the effect of various nanomaterials on the wettability, and particularly the brine phase contact angle, of a sand stone reservoir. The nanomaterials used are Magnesium/Aluminum Layered Double Hydroxide, Silica/Zirconia, and a combination of $\mathbf{8 0 . 0 \%}$ Magnesium/Aluminum Layered Double Hydroxide (Mg/Al-LDH) and 20.0\% Silica/Zirconia (Zi/Zr). The results suggest that a concentration of $4.0 \mathrm{~g} / \mathrm{L}$ of Magnesium/Aluminum Layered Double Hydroxide (Mg/Al-LDH) decreases the brine phase contact angle, in the presence of oil, from $66^{\circ}$ to $60^{\circ}$ in 0.033 minute as opposed to Silica/Zirconia which increases the brine phase contact angle to $68^{\circ}$ in the same time interval. The combination of both nanoparticles results in a decrease of $1.0^{\circ}$ in the brine phase contact angle indicating that Silica/Zirconia (Zi/Zr) lowers the efficiency of Magnesium/Aluminum Layered Double Hydroxide's adsorption to the sandstone surface.

\section{Keywords}

Nanomaterials, Wettability Alteration, Oil Recovery Mechanism 


\section{Introduction}

Wettability of rocks is classified into five categories, which are Water Wettability, oil wettability, neutral or intermediate wettability, fractional wettability, and finally, mixed wettability. In water-wet reservoirs, the reservoir rock is preferentially wetted with water which occupies the small pores and contacts most of the rock surface forming a thin film of water that coats the formation matrix [1] [2]. For effective oil transport and recovery, the water-wet condition is a favourable one [3].

In this study, contact angle measurement and analysis are rigorously explained and applied. The contact angle is one of the quantities that measure the wettability of a rock/fluid system. It is the angle measured through the liquid where a solid interface is in contact with a liquid/vapour interface. There are several existing methods for contact angle measurement such as tilting plate method, the capillary rise method, and the sessile drop method.

The contact angle is defined as the edge of a droplet of fluid placed on a flat surface. The edge of the droplet when in contact with a surface is divided into three different regions, which are a free surface, a planar interface and a transition region. The planar interface is the region where the droplet adheres to the solid surface and is different from the nature of the liquid. The transition region connects the spherical cap to the droplet planar portion. The radii and the tangent are varying accordingly from zero at the planar interface to pi-theta at the spherical cap. This will change the energy with changes in separation when they get close to each other [4].

This contact angle measurement method involves depositing a water, which is brine in the majority of the cases so as to simulate the reservoir saline condition, drop on the rock surface and adding volume to the drop until the maximum volume allowed is reached without increasing the three-phase line. The advancing angle is the maximum possible angle measured resulting from the volume increase. The increase in volume step is followed by a volume removal one where the maximum volume that can be extracted before disturbing the drop profile's geometry is removed and the resulting contact angle is measured [5]. This angle is the receding angle which when subtracted from the advancing contact angle yields a value referred to as the contact angle hysteresis The difference between the advancing angle and the receding angle is the hysteresis contact angle $H=\theta a-$ $\theta r[6]$.

\section{Structure of Nanomaterials and Their Applications in the Oil Industry}

Nanotechnology is the technology that has enabled us to synthesize material at the nano-structural form. One nano-meter (nm) is one billionth of a meter or approximately 5 silicon atoms aligned in one line, Figure 1 shows the nano-meter scale compared to other material sizes [7]. Nanotechnology is a complex interdisciplinary science that has many categories like nano-chemistry, nanophysics, Nanomaterial, nano-electronics and nanobionics.

Applications of Nanotechnology. The use of Nanomaterial in the petroleum field is extremely essential, as now we need new technology to be able to deplete our reservoir or enhance the material being used to make more than one function at the time and this is possible through the use of Nanomaterial. The use of Nanomaterial in the petroleum field is wide; we can use it in the drilling operation, in completion and production in most of the process made.

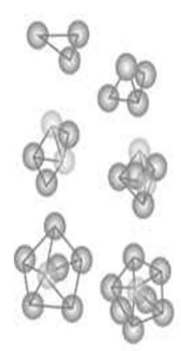

Clusters

0D

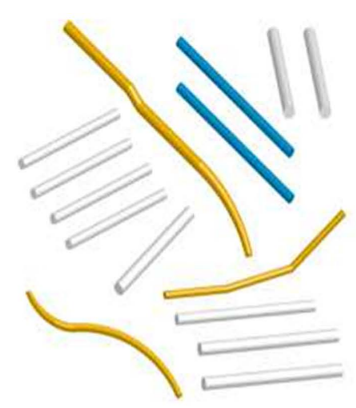

Nanotubes, fibers and rods

1D

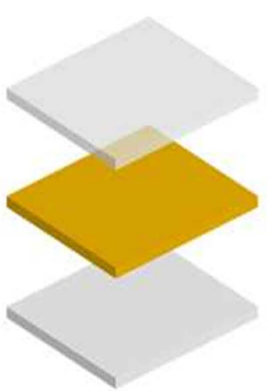

Films and coats 2D

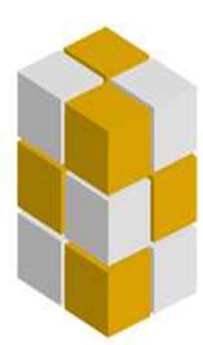

Polycrystals

3D

Figure 1. Classification of nanomaterials. 
Classification of Nanomaterials. The principle sorts of nanostructured materials focused around the measurements of their structural components are: zero-dimensional (0-D), one-dimensional (1-D), two-dimensional (2-D) and three-dimensional (3-D) nanomaterials. Zero-dimensional nanomaterials incorporate nano-cluster materials and nano-dispersions, i.e. materials in which nanoparticles are detached from one another. One-dimensional Nano-materials are nano-fiber (nano-rod) and nano-tubular materials with fiber (rod, tube) length from $100 \mathrm{~nm}$ to several microns [8]. Two-dimensional nanomaterials are thin films (coatings) with nano-meter thickness. Structural components in 0-D, 1-D and 2-D nanomaterials can be appropriated in a fluid or robust perceptible framework or be connected on a substrate. Three-dimensional Nanomaterials incorporate powders, sinewy, multilayer and polycrystalline materials in which the 0-D, 1-D and 2-D structural components are in close contact with one another and structure interfaces. A vital kind of three-dimensional nanostructured material is a minimized or merged (mass) poly-crystal with nano-size grains, the whole volume of which is loaded with those nano-grains, free surface of the grains is for all intents and purpose missing, and there are just grain interfaces. The arrangement of such interfaces and "vanishing" of the nanoparticle (nano-grain) surface is the essential distinction between three-dimensional smaller nanomaterials and nano-crystalline powders with different degrees of agglomeration that comprise of particles of the same size as the minimized nanostructured materials [9]. Figure 2 shows the difference of the shapes and structure of 0D, 1D, 2D and 3D.

Nanomaterials and Reservoir Wettability. The use of nanomaterial in the field of wettability alteration has made some promising results in the enhancement of oil production. The use of nanomaterial made these promising results as its size is in the nanometer scale, which enables it to move through the tight pore spaces and fully flush the reservoir to reach maximum depletion which Having a nanomaterial that would enable altering the wettability of the reservoir from oil-wet to water-wet means that the ultimate oil recovery could be reached.

Initially, before the nanofluid alters the wettability, the oil droplet has a 180-degree contact angle with the surface, but when the nanofluid is presents it contracts this angle to nearly 1-degree, and the result is a wedge film [10]. If there is a one layered wedge film its force will be higher than a two layered wedge film. This wedge film will be the main acting reason to separate the oil from the formation surface. This will impart the oil particles that are adhered to the rock surface to be removed from the rock and flow and then the nanoparticles adhere to the rock surface. The complete spreading of the nanofluid will make the oil droplet separate completely from the surface of the rock, when the angle reaches zero [11]. Thus, at this point, we can safely say that there is a successful alteration of the wettability as we changed the contact angle of the oil from 180-degree to zero degree that is a complete separation cycle.

\section{Nanomaterials Used in Experimentation}

\subsection{Magnesium/Aluminium Layered Double Hydroxide, (Mg/Al-LDH)}

As Figure 2 illustrate that Structure of Layered Double Hydroxides. The (Mg/Al-LDH) has the ability to combine two-dimensional layered material and intercalation technique, which gives us a new area for developing new material with desired functionality [12]. The (Mg/Al-LDH) has a chemical composition general formula of $\mathrm{M}_{1-\mathrm{x}}^{\mathrm{II}} \mathrm{M}^{\mathrm{III}}{ }_{\mathrm{x}}(\mathrm{OH})_{2} \mathrm{~A}^{\mathrm{n}-}{ }_{\mathrm{x} / \mathrm{n}} \mathrm{yH} \mathrm{H}_{2} \mathrm{O}$, where $\mathrm{M}^{\mathrm{II}}$ and $\mathrm{M}^{\mathrm{III}}$ are divalent and trivalent metal Cations and An- is an $\mathrm{n}$-vacant anion. They possess a crystal like structure composed of positively charged hydroxide layers. Mg/Al-LDH is an effective material in this experiment as it has great potential in adhering or adsorbing on to surfaces which is main focus of the material being used in the enhancement of oil recovery.
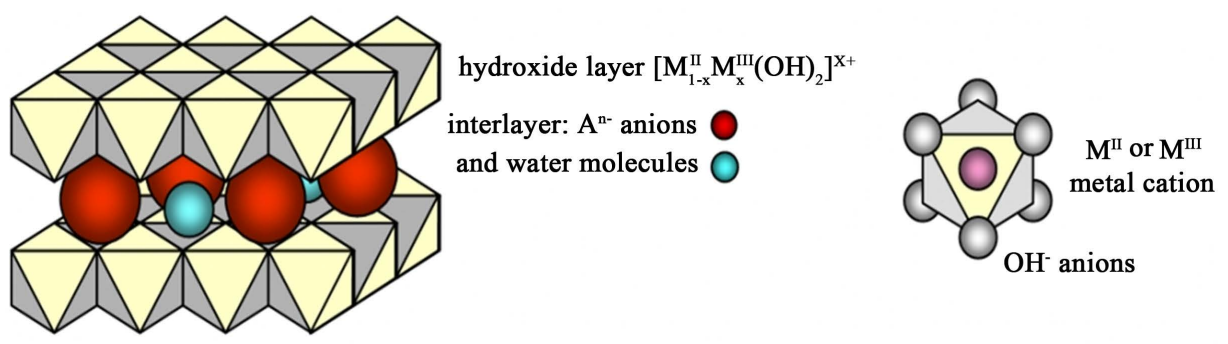

Structure of layered double hydroxide

Figure 2. Structure of layered double hydroxides. 


\subsection{Silica/Zirconia (Si/Zr)}

Silicon and zirconium oxides have been studied extensively in the past years due to their superior physicochemical properties. These properties are classified as follows: higher thermal and chemical stability, hardy mechanical strength, catalytic activity and strong surface acidity [13]. When dispersed in distilled water or brine, Aluminium oxide nanoparticles proved their efficacy in reducing oil viscosity and thus, enhancing oil recovery. Furthermore, hydrophobic silicon oxide nanoparticles change the wettability of rocks upon dispersion in ethanol. Using ethanol solely as an enhanced oil recovery agent reduces the oil-water interfacial tension. Magnesium oxide exhibited low capability in enhancing recovery as it causes permeability impairment when dispersed in brine or distilled water. The use of brine-dispersed Aluminium oxide and ethanol-dispersed Silicon oxide nanoparticles for improving oil recovery is recommended [14].

Initially, all rocks are believed to be water wet, prior to the migration of oil to them from the source rock. Following migration, oil got trapped and saturated the rock in tight spots, thus replacing the water and becoming oil wet. After the development of nanomaterial, we are now able to reach tight spots that we not could reach before, as this technology had not yet been applied. The wettability alteration of the rock mainly depends on the separation of the oil from the surface of the rock and this is called the disjoining pressure, and will be thoroughly explained in the coming section, which is related to the contact angle of the oil droplet with the surface and the interfacial tension of the fluid.

The objective of this study to investigate the effect of various nanoparticles on the wettability of a sandstone reservoir where Magnesium/Aluminum Layered Double Hydroxide (Mg/Al-LDH), Silica/Zirconia (Si/Zr), and a mixture of both containing 80\% Magnesium/Aluminum Layered Double Hydroxide and 20\% Silica/Zirconia by weight are deposited on sandstone rock plates and the corresponding contact angles are measured and recorded. The concentration is kept constant at $4.0 \mathrm{~g} / \mathbf{L}$ and the changes in contact angles are to be taken as indications of changes in wettability.

\section{Methodology}

The aim of the research is to investigate the effect of various nanomaterials on the wettability of a sandstone reservoir and particularly the effect of these nano-materials on the water phase contact angle with the surface of the rocks. Changes in the reservoir rock wettability are of interest in the oil field industry as they reflect on the amount of oil recovered from the reservoir. When the reservoir wettability is altered from water-wet to oil-wet, severe impairment is caused to the productivity, therefore, treatments that lead the reservoir to a more water-wet condition are favourable ones.

The nanomaterials under investigation are Magnesium/Aluminum Layered Double Hydroxide (Mg/Al-LDH), Silica/Zirconia (Si/Zr), and a mixture of containing $\mathbf{8 0 . 0 \%}$ Magnesium/Aluminum Layered Double Hydroxide (Mg/Al-LDH) and $\mathbf{2 0 . 0 \%}$ Silica/Zirconia (Si/Zr) by weight. The use of the Mg/Al-LDH is justified by the fact that none of the previous researchers tested its efficacy in the oil industry in contrast to oxides that have been extensively used in the field of oil recovery.

The concentration of the above mentioned nano-materials was kept constant at $\mathbf{4 . 0} \mathbf{~ g} / \mathbf{L}$ in the study making the type of material the variable. The study is conducted at ambient condition except for the saturation of core plugs that was conducted at a pressure of $\mathbf{2 0 0 0} \mathbf{~ p s i}$. The different instruments used throughout the study are explained in the experimental section.

The contact angle meter was used for measuring the contact angle that each nano-fluid makes with the rock in an attempt to settle on the one with the greatest positive impact on oil productivity.

The following are the wettability categories that surfaces lie in depending upon the range in which their contact angle falls:

\begin{tabular}{cc}
$\mathbf{0}^{\circ} \leq \boldsymbol{\theta}<\mathbf{9 0}^{\circ}$ & Water-wet \\
$\boldsymbol{\Theta}=\mathbf{9 0}^{\circ}$ & Neutral or Intermediate wet \\
$\mathbf{9 0}^{\circ}<\boldsymbol{\theta} \leq \mathbf{1 8 0 ^ { \circ }}$ & Oil-wet \\
\hline
\end{tabular}

The relation between the contact angle and the interfacial energies is governed by Young's equation: 


$$
o_{o s}^{\prime}-o_{w s}^{\prime}=o_{o w}^{\prime} \cos \theta
$$

$\theta$ = Contact angle measured through the water phase at Rock/Oil/Brine interface;

$o_{o s}^{\prime}=$ Interfacial energy between Solid and Oil, (dyne/cm)

$o_{w s}^{\prime}=$ Interfacial energy between Solid and Water, (dyne/cm),

$o_{o w}^{\prime}=$ Interfacial energy or tension between Oil and Water, (dyne/cm) (Engler, (2010)).

Contact Angle Measurement. Several contact angle measurement techniques are present such as the tilting plate method, the capillary rise method, and the sessile drop method. The method that is most widely used in the petroleum industry is the sessile drop method [15]. The sessile drop measurement is conducted by placing a drop of water on a mineral surface that is suspended below the oil's surface horizontally [1]. The measurement takes place by taking a photograph of the system where the angle is measured through water, that is, the denser phase [15]. This is the basic principle of the sessile measurement technique. Modifications carrying different natures were introduced to the sessile drop method. This work explains the "Sessile - Add and Remove Volume Method" as it is the method of measurement adopted by the contact angle meter device that is used for measuring contact angles in the experimental section.

Limitations Associated with Contact Angle Measurement. One of the problems encountered during contact angle measurements is contact angle hysteresis where a liquid drop can make several stable contact angles with the rock surface. Hysteresis is a result of surface heterogeneity and roughness [16]. Another cause of hysteresis while measuring contact angles is surface immobility where the surface does not allow the necessary motion for the fluid to reach an equilibrium contact angle value [15]. Surface roughness influences the oil/brine/ solid contact line, such that the contact angle is fixed only on smooth surfaces. Figure 3 illustrates that Water advancing and receding contact angles measured by the sessile drop method.

\section{Experimental Work and Procedures}

\subsection{Materials}

The materials used in the experiment were core samples from a sandstone reservoir obtained from a well producing in the Western Desert, synthetic brine prepared in the Lab. with salinity of 50,000 ppm, the composition of the brine used in experiment was $5.0 \mathrm{wt} \%$ of $\mathrm{NaCl}$. The density of brine was $1.047 \mathrm{gm} / \mathrm{cm}^{3}$, oil that has a density of $0.9554 \mathrm{~g} / \mathrm{mL}$, and API gravity of $17^{\circ}$. Nanomaterials obtained were Si/Zr, Mg/Al-LDH and a mixture of $80.0 \% \mathrm{Mg} \mathrm{Al}-\mathrm{LDH}$ and $20.0 \% \mathrm{Si} / \mathrm{Zr}$ by weight. A concentration of $4.0 \mathrm{gm} / \mathrm{L}$ of each nanomaterial was prepared by dispersing it in brine using an ultra-sonic bath. The ultrasonic bath was carried out with the aim of ensuring that the nano-solution is stable and homogeneous.

\subsection{Setup and Procedures for Experimental}

Core plugging was done to the sample rock using the plugging machine in the university Lab.7 cores sample were cut off from the sample rock where four core plates samples had average diameter $38.07 \mathrm{~mm}$, lengths ranging from 8.24 to $11.77 \mathrm{~mm}$.

The core samples were trimmed using the Trim Saw and then they were left into the Dean stark device to be cleaned from any undesirable fluids in the pores. Then the core samples were put into the oven to be dried and it

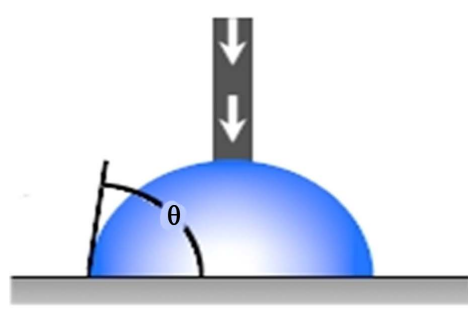

advancing angle

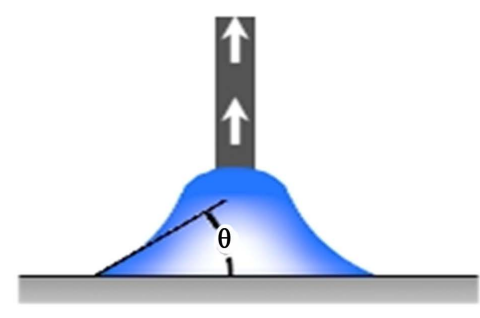

receding angle

Figure 3. Water advancing and receding contact angles measured by the sessile drop method. 
was heated at $64^{\circ} \mathrm{C}$ as above this temperature the clays in the samples might break down affecting porosity and permeability of the cores. Routine core analysis was done to get porosity and absolute permeability using Helium Porosi-meter and Air Permeameter, then the four core plugs (Plates) was put inside the manual saturator to be saturated with brine and measure its saturation at pressure 2000 psi and ambient temperature for eight or ten hours. Table 1 show that the routine core analysis results for core plate samples used in this study.

Each of the four core plates were injected with brine and different nanomaterial at constant concentration $\mathbf{( 4 . 0 \%}$ by wt) and were achieved the measurement of contact angles for their and surface tension measured between air, brine and/or different nanomaterial phases using a contact angle meter and K100 Tensiometer into the Central Metallurgical Research institute. Figure 4(a) and Figure 4(b) show that Contact Angle Meter, CMRDI and Nano-fluid droplet being deposited on the rock's surface as detected by the contact angle meter's software.

\subsection{Surface and Interfacial Tension}

The change in surface or interfacial tension between oil, brine and several of nano-fluid, and air are the main mechanism when wettability reversal to water-wet condition, reduction of interfacial tension will lead to a reduction of the capillary pressure within the pores. Surface tension is measured in the laboratory by a Tensiometer-K100, which can be used by DuNouy ring. Figure 5 illustrate that the surface tension apparatus used to measure of the surface tension values $(\mathrm{mN} / \mathrm{m})$ for each distilled water, brine, oil and version of nano-fluids for different materials.

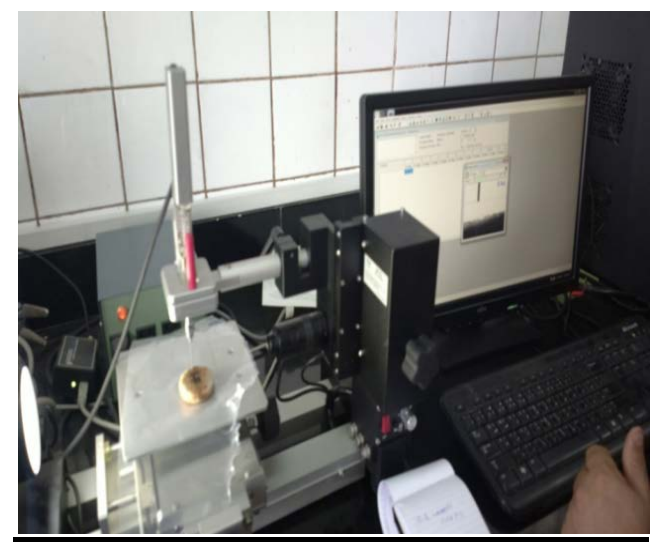

(a)

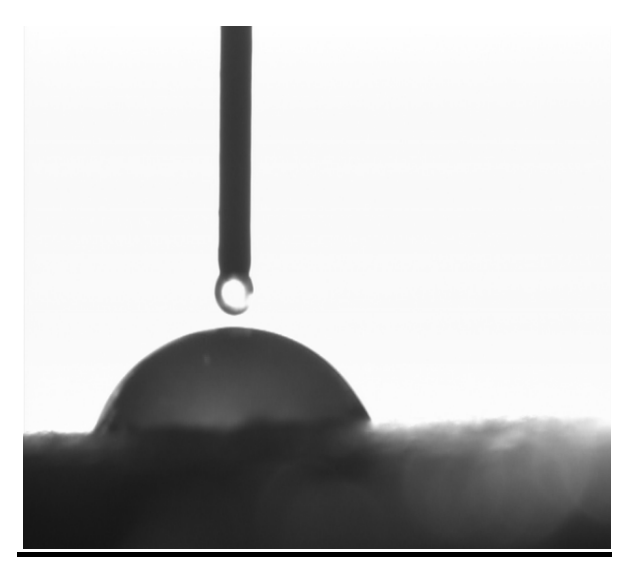

(b)

Figure 4. (a) Contact angle meter, (CMRDI); (b) nanofluid droplet being deposited on the rock's surface as detected by the contact angle meter's software.
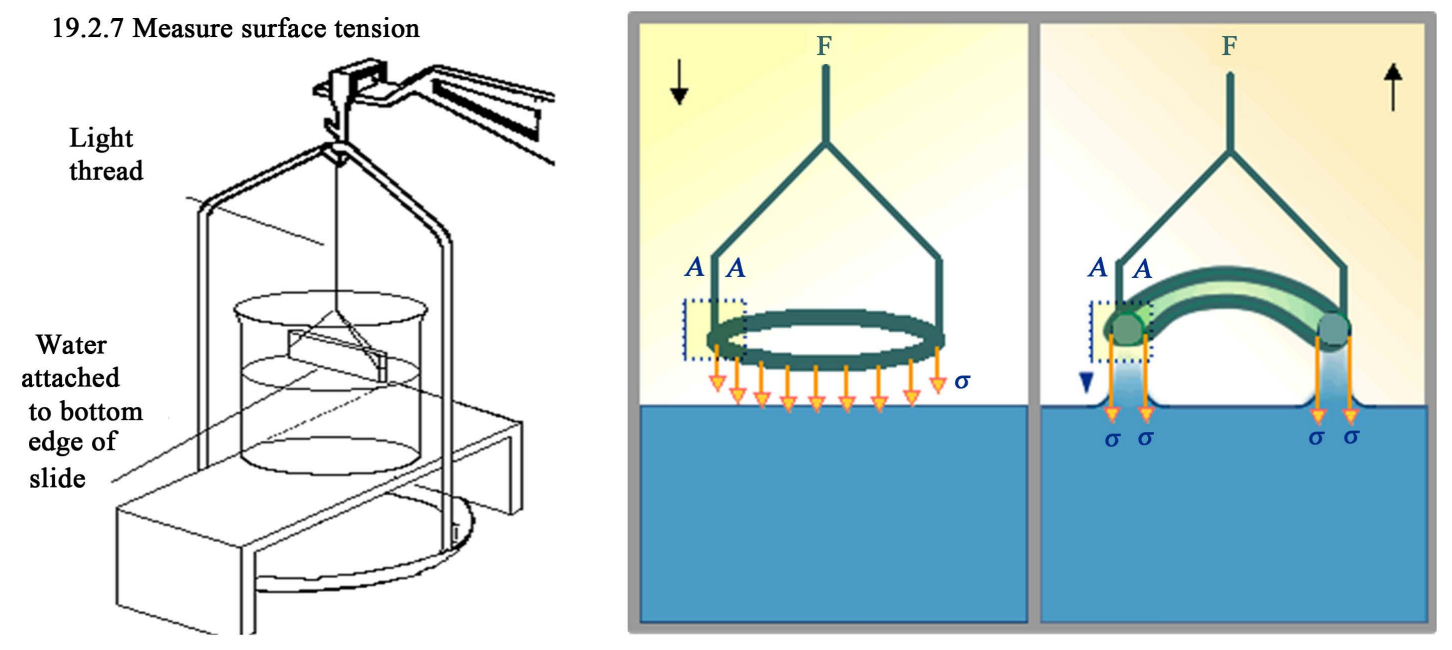

Figure 5. Surface tension apparatus measured and procedures. 
Table 1. Routine core analysis results for core plate samples.

\begin{tabular}{ccccccccccccc}
\hline $\begin{array}{c}\text { Sample } \\
\text { No }\end{array}$ & Weight & Diameter & Length & $\begin{array}{c}\text { Bulk } \\
\text { Volume }\end{array}$ & $\begin{array}{c}\text { Grain } \\
\text { Density }\end{array}$ & $\begin{array}{c}\text { Pore } \\
\text { Volume }\end{array}$ & Porosity & $\begin{array}{c}\text { Cal. } \\
\text { Pore } \\
\text { Volume }\end{array}$ & $\begin{array}{c}\text { Absolute } \\
\text { Permeability }\end{array}$ & $\begin{array}{c}\text { Oil } \\
\text { Saturation }\end{array}$ & $\begin{array}{c}\text { Initial } \\
\text { Water } \\
\text { Saturation }\end{array}$ \\
\cline { 2 - 13 } & $\mathbf{g m}$ & $\mathbf{m m}$ & $\mathbf{m m}$ & $\mathbf{m m}$ & $\mathbf{g m} / \mathbf{c m}^{\mathbf{3}}$ & $\mathbf{m m}$ & $\mathbf{m}$ & $\mathbf{\%}$ & $\mathbf{m d}$ & $\mathbf{\%}$ & $\mathbf{\%}$ \\
\hline Plate 1 & 20.90 & 38.14 & 9.04 & 10.33 & 2.41 & 1.64 & 15.88 & 1.53 & 2201.76 & 93.7 & 6.3 \\
Plate 2 & 18.72 & 38.04 & 8.24 & 9.36 & 2.39 & 1.48 & 16.35 & 1.53 & 2378.90 & 97.2 & 2.8 \\
Plate 3 & 21.33 & 38.08 & 9.57 & 10.90 & 2.39 & 1.99 & 18.26 & 1.67 & 2595.97 & 84.3 & 15.7 \\
Plate 4 & 24.00 & 38.02 & 11.77 & 13.36 & 2.42 & 3.44 & 25.75 & 2.01 & 2698.79 & 58.4 & 41.6 \\
\hline
\end{tabular}

The main difference between these two is the places where it occurs. Surface tension is defined to a single liquid surface, whereas the interfacial tension is defined to the interface of two immiscible liquids. Surface tension is actually a derivation of interfacial tension where force from the second surface is negligible or zero.

In addition to, we can be determined the interfacial tension after measuring of contact angles for several solutions of nano-fluids and versus oil and surface tension measured for their solutions. Its calculated by used the follows as means equation [17]:

$$
\gamma_{s l}=\frac{\left(\sqrt{\gamma_{l a}}-\sqrt{\gamma_{s a}}\right)^{2}}{1-0.015 \sqrt{\gamma_{l a} \gamma_{s a}}}
$$

This equation is called geometric of determined of interfacial tension for solutions versus oil. where:

$\gamma_{s l}=$ Interfacial Tension calculated for oil-rock/nano-fluids, $\mathrm{mN} / \mathrm{m}$;

$\gamma_{s a}=$ Surface Tension measured for oil-rock and air, $\mathrm{mN} / \mathrm{m}$;

$\gamma_{l a}=$ Surface Tension measured for nano-fluids and air, $\mathrm{mN} / \mathrm{m}$.

\section{Results and Discussion}

Nanomaterials are being used in the oil industry in the domain of Enhanced Oil Recovery where they are injected into core samples in the laboratory and the resulting increase in oil recovery is recorded. Metal oxides in the nanoscale such as aluminum oxide, silica, iron oxide, and nickel oxide are being used; however, hydroxides were never attempted with this purpose. As far as the contact angle principle is concerned, [18] postulate that a concentration of $\mathbf{4 . 0} \mathbf{~ g} / \mathbf{L}$ of $\mathrm{SiO}_{2}$ nanoparticles suspended in water can alter the wettability of a carbonate reservoir from strongly oil-wet to strongly water-wet. The oil phase contact angle changed from $35^{\circ}$ to $135^{\circ}$. Their results prove that significant amounts of oil can be recovered after water is injected into the core plug aged with $\mathrm{SiO}_{2}$ nanofluids.

Moreover, the concentration of the nanoparticles enhances the oil recovery as when we increase the concentration of the nanoparticles in brine mix solution (nanoparticles in aqueous phase) the interfacial tension and the contact angle decreases [19]. The effect of $\mathrm{\gamma}-\mathrm{Al}_{2} \mathrm{O}_{3}$ nanoparticles on the wettability of an Iranian carbonate reservoir was explored by [20]. He suggests that $\mathrm{\gamma}-\mathrm{Al}_{2} \mathrm{O}_{3}$ nanoparticles could adsorb on a carbonate surface altering its wettability from oil-wet to water-wet. The most significant change in oil phase contact angle corresponded to a 0.5 wt\% concentration of $\mathrm{\gamma}-\mathrm{Al}_{2} \mathrm{O}_{3}$ nanofluid. A $\mathbf{0 . 5} \mathbf{~ w t} \%$ concentration of $\mathrm{\gamma}-\mathrm{Al}_{2} \mathrm{O}_{3}$ nanoparticles caused the maximum change in contact angle. At this concentration raised the amount of oil recovered by $11.25 \%$ upon injection into the core sample.

Roustaei and Bagherzadeh postulate that a $\mathbf{4 . 0}$ g/L concentration of $\mathrm{SiO}_{2}$ nanoparticles could introduce considerable alteration to the rock wettability from oil-wet to water-wet [18]. To settle on the optimum concentration of $\mathrm{SiO}_{2}$ nanoparticles to be injected into a carbonate core sample, the researchers applied their study on a concentration range of $\mathbf{1 . 0}$ - $\mathbf{6 . 0} \mathbf{g} / \mathbf{L}$. Seven carbonate plates were cleaned polished, trimmed; to minimize contact angle hysteresis, and saturated with crude oil. Oil droplets were deposited on the carbonate surfaces and the oil phase contact angle, in the presence of brine, was measured. 
A graph of oil phase contact angle (degrees), in the presence of brine, versus several nano-fluid concentrations $(\mathrm{g} / \mathrm{L})$ was plotted and so the optimum concentration appeared to be $4.0 \mathrm{~g} / \mathrm{L}$. The $4.0 \mathrm{~g} / \mathrm{L}$ concentration changed the oil phase contact angle from $35^{\circ}$ to $135^{\circ}$ indicating a wettability shift from oil-wet to water-wet. The change in angle was a consequence of the increase in the interfacial tension between oil and water according to Young's equation. The wettability alteration reflected on oil recovery by an increase to $\mathbf{7 6 . 0 \%}$ in the amount of oil recovered after nano-fluid injection. Table 2 shows that the average contact angle measurement for brine solution, $\mathrm{Mg} / \mathrm{Al}-\mathrm{LDH}$ phase solution, $\mathrm{Si} / \mathrm{Zr}$ phase solution and mixture with $\mathbf{8 0} \%$ by wt of $\mathrm{Mg} / \mathrm{Al}-$ LDH phase and $20 \%$ by wt of Si/Zr phase solution. All of one, these phases used at constant concentration $\mathbf{4 . 0}$ g/L of nanomaterials.

Four core plates of a length of approximate $1.0 \mathrm{~mm}$ each and cleaning samples using a trimming machine and polished to achieve a flat and relatively smooth surface which used to measure of contact angle are accuracy values results, then these sample plates were saturated with oil at room temperature and a pressure of $2000 \mathrm{psi}$. Four different solutions were prepared such that each solution is to be deposited on one of the rock plates using a syringe.

The four solutions were: brine (used as a control to test the initial reservoir rock wettability), Mg/Al-Layered Double Hydroxide suspended in brine, Silica/Zirconia suspended in brine, and the mixture of both nanoparticles was also suspended in brine.

The entire time interval taken to measure contact angles for each sample of the four was 2000 milliseconds ( 0.033 minute). For all samples, the maximum recorded deviation between contact angle readings was found to be $16^{\circ}$. As a result, the contact angle readings reported contain a maximum error of $\pm 8^{\circ}$. It entails depositing a water droplet on the rock's surface and adding volume to it and measuring the contact angle, which is in this case referred to as the advancing contact angle. The volume increase step is followed by a volume decrease one where volume is extracted from the drop and the contact angle is measured.

For the brine sample, the brine phase contact angle, in the presence of oil, was $65.56^{\circ}$ indicating an initially water-wet condition of the sandstone rock sample. Then, measured for the $\mathrm{Mg} / \mathrm{Al}$ Layered Double Hydroxide (Mg/Al-LDH), the brine phase contact angle, it’s decreased to $59.7^{\circ}$; so indicating that the rock is becoming more water-wet. In case of Silica/Zirconia, the brine phase contact angle increased to $67.9^{\circ}$ suggesting a decrease in water-wetness and consequently, an inclination towards oil-wetness. Finally, for the mixture of both nanoparticles, the brine phase contact angle decreased slightly to $65^{\circ}$ implying that Silica/Zirconia renders the $\mathrm{Mg} / \mathrm{Al}$ Layered Double Hydroxide inefficient. Figure 6 shows that the contact angle values for brine and several of nanomaterials.

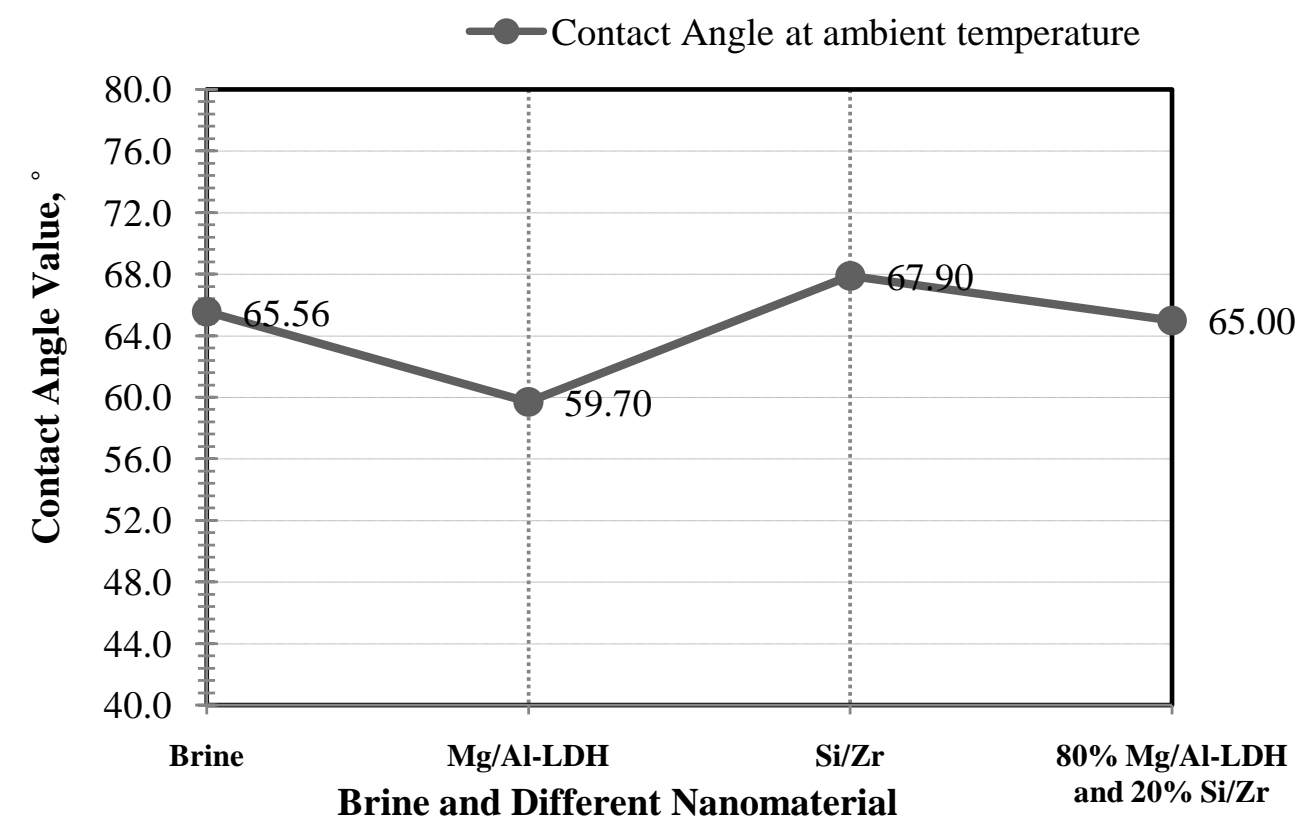

Figure 6. Contact angle measurement for brine and various nanomaterials. 
Table 2. Average contact angle measured for each nano-material used.

\begin{tabular}{cc}
\hline Material Used & Nano = Fluid/Oil-Rock Contact Angle Measuring (Degrees) \\
Brine & 65.56 \\
Mg/Al-LDH & $\underline{59.70}$ \\
$\mathbf{S i} / \mathbf{Z r}$ & 67.90 \\
$\mathbf{8 0 . 0} \% \mathbf{M g} / \mathbf{A l}-\mathbf{L D H}+\mathbf{2 0 . 0} \% \mathrm{Si} / \mathbf{Z r}$ (by Weight) & 65.00 \\
\hline
\end{tabular}

\section{Interfacial Tension}

The difference between interfacial tension and surface tension is the liquid-liquid interface instead of the liquidair interface. Interfacial tension can be used to describe immiscibility of these two liquids. Consider the interface between the phases. The molecules on the first surface have forces acting upon it from the first liquid and from the surface molecules of the second liquid and vice versa. If the force on the surface molecules from the first liquid (cohesive forces) equals the force from the second surface (adhesive forces) these two liquids will mix. If these forces are unequal these liquids will not mix.

As Table 3 and Figure 7 illustrated the behaviour of oil-distilled water-brine and several of nanomaterial for measured the surface tension and calculated for interfacial tension at ambient temperature. The oil with air was observed to demonstrate decreasing surface and interfacial tension than distilled water and brine with air at room temperature. The laboratory work can be simplified by show the less value of surface tension measured or Calculated of Interfacial Tension were observed at the solution of Si/Zr with air and $\mathrm{Si} / \mathrm{Zr}$ solution with oil than the other nanomaterial either Mg/Al-LDH with air or mixed Si-Zr \& Mg/Al-LDH with air and with oil.

For example, nanoparticles can be directed to self-assemble into thin films at an oil/brine interface by manipulating the solid/brine or solid/nano-fluid and solid/oil surface tensions. However, if the attractive forces had been occur at the interface between two phases (interfacial tension). So the interfacial tension is an important factor in tertiary or enhanced oil recovery processes and in calculating of reserves oil reservoir.

\section{Conclusion and Recommendations}

- The use of Mg/Al-Layered Double Hydroxide (Mg/Al-LDH) as nanoparticles dispersed in brine is highly supported. For a sandstone reservoir, it decreased the brine phase contact angle, in the presence of oil, by $\mathbf{6}^{\circ}$ in a period of 2000 milliseconds ( 0.033 minute).

- Silica/Zirconia nanomaterial ( $\mathrm{Si} / \mathrm{Zr}$ ) dispersed in brine is not to be used for the purpose of wettability alteration from oil-wet to water-wet as it yields an increase in the brine phase contact angle by $2.34^{\circ}$ in 2000 milliseconds (making the rock less water-wet). Silica/Zirconia causes wettability to shift towards oil-wet which is an unfavourable condition in the oil industry as it has adverse effects on oil recovery.

- When mixed with Silica/Zirconia nanoparticles (Si/Zr), the effect of Mg/Al Layered Double Hydroxide nanoparticles (Mg/Al-LDH) in increasing water-wetness decreases significantly.

- It can be inferred from the results that $\mathrm{Mg} / \mathrm{Al}$ Layered Double Hydroxide nanoparticles (Mg/Al-LDH) dispersed in brine adsorb on the surface of the rock decreasing the contact angle, thereby, resulting in an increased water-wetness condition. Silica/Zirconia nanoparticles ( $\mathrm{Si} / \mathrm{Zr}$ ) dispersed in brine cause oil to decrease the cohesive forces between brine and the rock's surface, thus the surface becomes less water-wet. This explains why when Mg/Al Layered Double Hydroxide (Mg/Al-LDH) is mixed with Silica/Zirconia its efficiency of increasing water-wetness decreases where it reduces the water phase contact angle only by $0.56^{\circ}$.

- $\mathrm{Mg} / \mathrm{Al}$ Layered Double Hydroxide forces (Mg/Al-LDH), the sandstone rock surface to become more hydrophilic as opposed to Silica/Zirconia (Si/Zr) which forces it to give up its affinity for water and to become hydrophobic.

- The results of this study recommend the adoption of Mg/Al Layered Double Hydroxide (Mg/Al-LDH) in the field of Enhanced Oil Recovery to alter the wettability of a sandstone reservoir rock from oil-wet to water-wet or to increase the water-wetness of an already water-wet sandstone reservoir.

- The effect explained was achieved in $\mathbf{0 . 0 3 3}$ minute, thereby, if the duration is extended for a whole day (24 hours), recognizable results are expected to be attained. These effects will reflect on the wettability measurement and subsequently on the amount of oil recovered from the reservoir. 


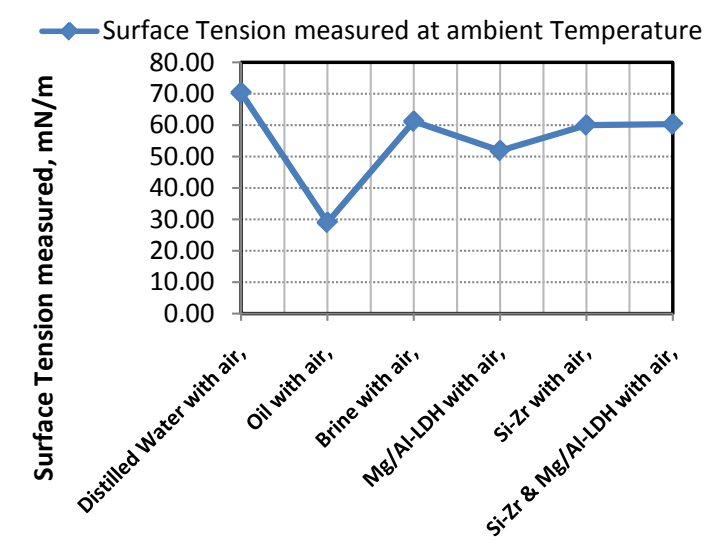

Distiiled water, Oil, Brine and various Nanomaterical Solution

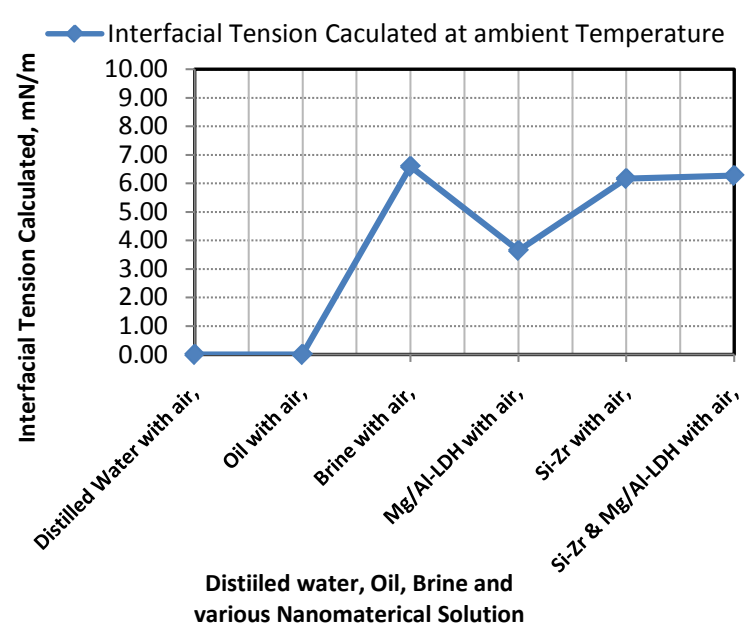
various Nanomaterical Solution

Figure 7. Surface tension measured and interfacial tension calculated versus distilled water, oil, brine and various Nanomaterial solutions.

Table 3. Average surface tension and calculated of interfacial tension versus distilled water, oil and type of solution.

\begin{tabular}{ccc}
\hline Type of Solution & Average Surface Tension Value $\mathbf{m N} / \mathbf{m}$ & Interfacial Tension Calculated $\mathbf{m N} / \mathbf{m}$ \\
\hline Distilled Water & 70.30 & ---- \\
Oil with air & 29.00 & ---- \\
Brine with air & 61.23 & $\underline{6.595}$ \\
Mg/Al-LDH with air & $\underline{51.90}$ & $\underline{3.650}$ \\
Si-Zr with air & 60.00 & 6.171 \\
Si-Zr \& Mg/Al-LDH with air & 60.30 & 6.274 \\
\hline
\end{tabular}

- In contrast, the application of Silica/Zirconia ( $\mathrm{Si} / \mathrm{Zr}$ ) in the industry with sandstone reservoirs is not recommended as it results in decreasing the affinity of the reservoir for water making it less water-water, thus yielding adverse effects on productivity.

\section{Acknowledgements}

Authors would like to express our gratitude and appreciation to petroleum engineering staff members at the American University in Cairo and Geologist. Marawan for allowing us to use the core lab under his supervision. We also would like to thank him for helping us carry out to complete our research work.

\section{References}

[1] Engler, T.W. (2010) Multiphase Phenomena-Fluid Flow in Porous Media. Chap. 5. 1-55.

[2] Anderson, W.G. (1986) Wettability Literature Survey-Part 1: Rock/Oil/Brine Interactions and the Effects of Core Handling on Wettability. Journal of Petroleum Technology, 38, 1125-1144.

[3] Schlumberger (2014) Oilfield Glossary. http://www.glossary.oilfield.slb.com/en/Terms.aspx?LookIn=term\%20name\&filter=water-wet

[4] Chengara, A., Nikolov, A.D., Wasan, D.T., Trokhymchuk, A. and Henderson, D. (2004) Spreading of Nanofluids Driven by the Structural Disjoining Pressure Gradient. Journal of Colloid and Interface Sciences, 280, 192-201. http://dx.doi.org/10.1016/j.jcis.2004.07.005

[5] Rame-Hart (2014) Contact Angle Goniometers and Tensiometers. Information on Contact Angle. http://www.ramehart.com/contactangle.htm

[6] Yuan, Y.H. and Lee, T.R. (2013) Contact Angle and Wetting Properties.

[7] Pokropivny, V., Lohmus, R., Hussainova, I., Pokropivny, A. and Vlassov, S. (2007) Introduction to Nanomaterials and 
Nanotechnology. University of Tartu, Ukraine.

[8] Tiwari, J. and Kim, K. (2011) Zero-Dimensional, One-Dimensional, Two-Dimensional and Three-Dimensional Nanostructured Materials for Advanced Electrochemical Energy Devices. Journal of Progress in Materials Science, 57, 724-803.

[9] Rahbar, M., Ayatollahi, S. and Ghatee, M.H. (2010) The Roles of Nano-Scale Intermolecular Forces on the Film Stability during Wettability Alteration Process of the Oil Reservoir Rocks. SPE 132616, Trinidad and Tobago Energy Resources Conference, Spain, 27-30 June 2010. http://dx.doi.org/10.2118/132616-MS

[10] Wasan, D.T., Nikolov, A. and Kondiparty, K. (2011) The Wetting and Spreading of Nanofluids on Solids: Role of the Structural Disjoining Pressure. Current Opinion in Colloid \& Interface Science, 16, 344-349. http://dx.doi.org/10.1016/j.cocis.2011.02.001

[11] Paul, M., Holcomb, D. and Ector, D. (2012) Application of Nanofluid Technology to Improve Recovery in Oil and Gas Wells. SPE International Oilfield Nanotechnology Conference, Noordwijk, 12-14 June 2012, SPE 154827.

[12] Nalawade, N., Aware, B., Kadam, V.J. and Hirlekar, R.S. (2009) Layered Double Hyroxides: A Review. Journal of Scientific \& Industrial Research, 68, 267-272.

[13] Wu, Z.G., Zhao, Y.X. and Liu, D.S. (2003) The Synthesis and Characterization of Mesoporous Silica-Zirconia Aerogels. Journal of Microporous and Mesoporous Materials, 68, 127-132. http://dx.doi.org/10.1016/j.micromeso.2003.12.018

[14] Ogolo, N.A., Olafuyi, O.A. and Onyekonwu, M.O. (2012) Enhanced Oil Recovery Using Nanoparticles. SPE Saudi Arabia Section Technical Symposium and Exhibition, Al-Khobar, 8-11 April 2012, SPE 160847. http://dx.doi.org/10.2118/160847-MS

[15] Anderson, W. (1986) Wettability Literature Survey_Part 2: Wettability Measurement. Journal of Petroleum Technology, 38, 1246-1262.

[16] Vijapurapu, C.S., Rao, D.N. and Kun, L. (2002) The Effect of Rock Surface Characteristics on Reservoir Wettability. SPE/DOE Improved Oil Recovery Symposium, Tulsa, 13-17 April 2002, SPE 75211.

[17] Kwok, D.Y. and Neumann, A.W. (1999) Contact Angle Measurement and Contact Angle Interpretation. Advances in Colloid and Interface Science, 81, 167-249.

[18] Roustaei, A. and Bagherzadeh, H. (2014) Experimental Investigation of $\mathrm{SiO}_{2}$ Nanoparticles on Enhanced Oil Recovery of Carbonate Reservoirs. Journal of Petroleum Exploration and Production Technology, 5, 27-33.

[19] Hendraningrat, L., Li, S. and Torsaeter, O. (2013) Effect of Some Parameters Influencing Enhanced Oil Recovery Process Using Silica Nanoparticles: An Experimental Investigation. SPE Reservoir Characterisation and Simulation Conference and Exhibition, Abu Dhabi, 16-18 September 2013, SPE 165955.

[20] Mohammadi, M.S., Moghadasi, J. and Naseri, S. (2014) An Experimental Investigation of Wettability Alteration in Carbonate Reservoir Using $\gamma-\mathrm{Al}_{2} \mathrm{O}_{3}$ Nanoparticles. Iranian Journal of Oil \& Gas Science and Technology, 3, 18-26. 